\title{
Assessment of Third Molar Impaction Pattern and Associated Clinical Symptoms in a Central Anatolian Turkish Population
}

\author{
Selmi Yilmaz ${ }^{a}$ Mehmet Zahit Adisen ${ }^{a} \quad$ Melda Misirlioglua Serap Yorubulut ${ }^{b}$ \\ ${ }^{a}$ Department of Oral and Maxillofacial Radiology, Faculty of Dentistry, and b Department of Statistics, \\ Faculty of Science and Letters, Kırıkkale University, Kırıkkale, Turkey
}

\section{Key Words}

Third molar impaction - Winter's classification - Pain .

Pericoronitis · Turkish population

\begin{abstract}
Objectives: The purpose of this study was to assess the pattern of third molar impaction and associated symptoms in a Central Anatolian Turkish population. Material and Methods: A total of 2,133 impacted third molar teeth of 705 panoramic radiographs were reviewed. The positions of impacted third molar teeth on the panoramic radiographs were documented according to the classifications of Pell and Gregory and of Winter. The presence of related symptoms including pain, pericoronitis, lymphadenopathy and trismus was noted for every patient. Distributions of obtained values were compared using the Pearson $X^{2}$ test. Nonparametric values were analyzed using the Mann-Whitney $U$ test and Kruskal-Wallis test. Results: The mean age of the subjects was $30.58 \pm 11.98$ years (range: 19-73); in a review of the 2,133 impacted third molar teeth, the most common angulation of impaction in both maxillaries was vertical $(1,177 ; 55 \%)$. Level $B$ impaction was the most common in the maxilla $(425 / 1,037 ; 39 \%)$, while level C impaction was the most common in the mandible $(635 / 1,096 ; 61 \%)$. Pain $(272 / 705 ; 39 \%)$ and pericoronitis $(188 / 705 ; 27 \%)$ were found to be the most common complications of impaction. Among
\end{abstract}

705 patients ( 335 males, 370 females), pericoronitis was more prevalent in males $(101 ; 30 \%)$ and usually related to lower third molars $(236 ; 22 \%)$. The retromolar space was significantly smaller in females $(p<0.05)$. Moreover, there was a significant difference in retromolar space for the area of jaw (maxillary: $11.3 \mathrm{~mm}$; mandibular: $14.2 \mathrm{~mm}$ ) and impaction level (A: 14.7 $\mathrm{mm} ; \mathrm{B}: 11.1 \mathrm{~mm} ; \mathrm{C}: 10.3 \mathrm{~mm} ; \mathrm{p}<0.05)$. Conclusion: The pattern of third molar impaction in a Central Anatolian Turkish population was characterized by a high prevalence rate of level $\mathrm{C} \mathrm{im-}$ paction with vertical position. Pain and pericoronitis were the most common symptoms usually associated with level A impaction and vertical position.

(c) 2015 S. Karger AG, Basel

\section{Introduction}

Tooth impaction is a pathological situation in which a tooth cannot or will not erupt into its normal functioning position [1]. In human dentition, the third molars have the highest impaction rate of all teeth [1]. The major factors related to tooth impaction are lack of space, limited skeletal growth, increased crown size and late maturation of the third molars [2]. Although impacted third molars may remain symptom free indefinitely, they could give cause for various symptoms and pathologies, such as

\begin{tabular}{ll}
\hline KARGER & $\begin{array}{l}\text { () 2015 S. Karger AG, Basel } \\
1011-7571 / 15 / 0252-0169 \$ 39.50 / 0 \quad \text { Karger }\end{array}$ \\
$\begin{array}{l}\text { E-Mail karger@karger.com } \\
\text { www.karger.com/mpp }\end{array}$ & $\begin{array}{l}\text { This is an Open Access article licensed under the terms of the } \\
\text { Creative Commons Attribution-NonCommercial 3.0 Un- } \\
\text { ported license (CC BY-NC) (www.karger.com/OA-license), } \\
\text { applicable to the online version of the article only. Distribu- } \\
\text { tion permitted for non-commercial purposes only. }\end{array}$
\end{tabular}

Dr. Mehmet Zahit Adisen

Department of Oral and Maxillofacial Radiology

Faculty of Dentistry, Kırıkkale University

TR-71450 Kırıkkale (Turkey)

E-Mail m_zahit@hotmail.com 


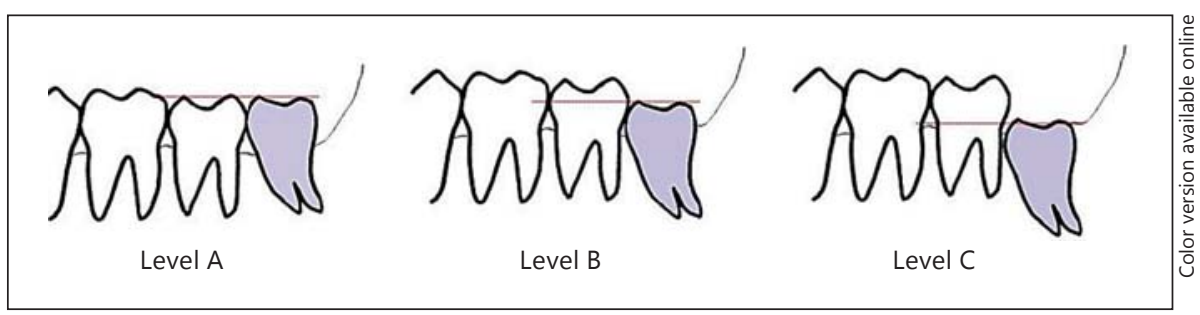

Fig. 1. Pell and Gregory classification. Level A: the occlusal plane of the impacted tooth is at the same level as the occlusal plane of the second molar (the highest portion of the impacted third molar is on a level with or above the occlusal plane); level B: the occlusal plane of the impacted tooth is between the occlusal plane and the cervical margin of the second molar (the highest portion of the impacted third molar is below the occlusal plane but above the cervical line of the second molar); level C: the impacted tooth is below the cervical margin of the second molar (the highest portion of the impacted third molar is below the cervical line of the second molar).
Fig. 2. Winter's classification. Vertical impaction: the long axis of the third molar is parallel to the long axis of the second molar (from 10 to $-10^{\circ}$ ); mesioangular impaction: the impacted tooth is tilted toward the second molar in a mesial direction (from 11 to $79^{\circ}$ ); horizontal impaction: the long axis of the third molar is horizontal (from 80 to $100^{\circ}$ ); distoangular impaction: the long axis of the third molar is angled distally/posteriorly away from the second molar (from -11 to $-79^{\circ}$ ); others (from 101 to $\left.-80^{\circ}\right)$.

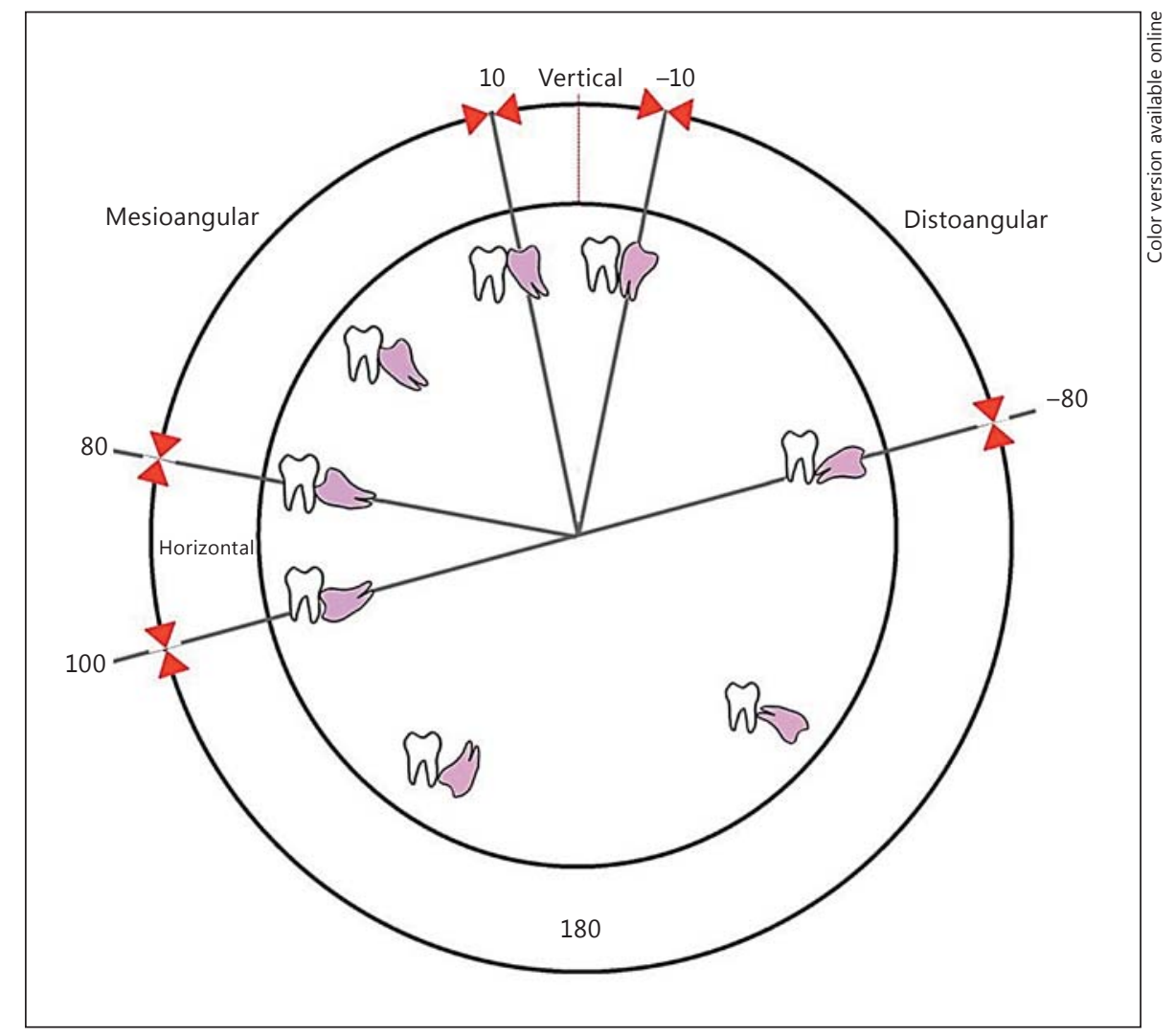

pericoronitis, pain, swelling, distal caries, bone loss, root resorption of adjacent teeth, odontogenic cysts and tumors [3]. It is considered that the occurrence of pathology resulting from impaction has a multifactorial origin [4]. Eruption status, position and angulation have an impact on these symptoms [4]. The decision whether or not to remove a mandibular third molar is probably one of the most frequent treatment decisions in the dental profession $[3,5,6]$. Hashemipour et al. [7] had noted that the anatomical position of impacted third molars shows im- portant variations which anticipate difficulty of extraction. Several methods have been used to classify impaction [4]. This classification is based on many factors, which are the level of impaction, the angulation of the third molars and the relationship to the anterior border of the ramus. The depth or level of maxillary and mandibular third molars can be classified using the Pell and Gregory classification system, where the impacted teeth are assessed according to their relationship to the occlusal surface of the adjacent second molar [2]. 


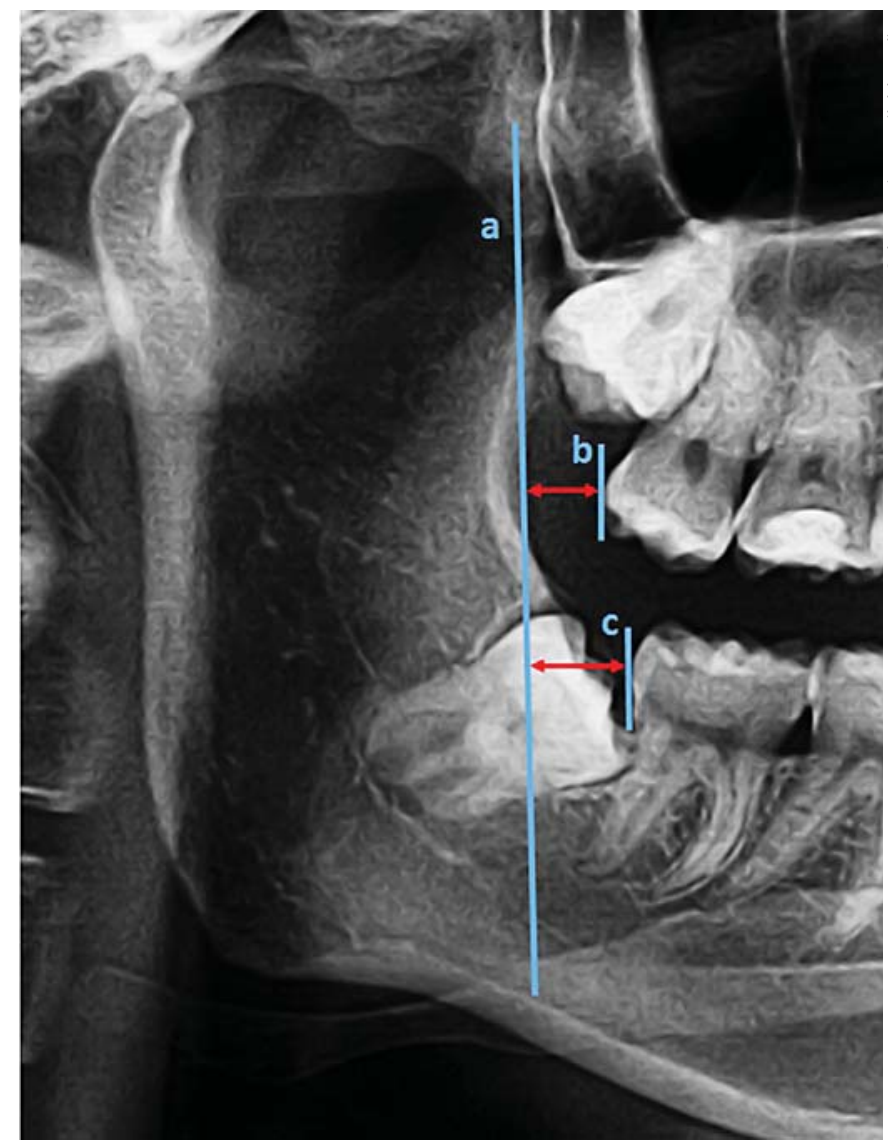

Fig. 3. Retromolar space measurements on panoramic radiography (red double-headed arrows; colors in the online version only): $\mathrm{a}=$ line from the anterior limit of the mandibular ramus; $\mathrm{b}=$ line from the posterior limit of the maxillary second molar; $c=$ line from the posterior limit of the mandibular second molar.

In previous studies on the Turkish population, the impacted molars were examined retrospectively using only radiological findings that included caries, bone loss and periodontal damage [3], or the clinical symptoms were evaluated only by comparing the status of eruption [8]. Hence, the aim of this study was to assess the third molar impaction pattern comprehensively by examining the status of eruption and angulation on panoramic radiographs and relating them to the associated clinical symptoms in a Central Anatolian Turkish population.

\section{Material and Methods}

A retrospective study was made of 705 patients (335 males and 370 females) with at least 1 impacted third molar detected on panoramic radiography at the Department of Oral and Maxillofacial Radiology from February to August 2014. The study plan was ap- proved by the administration of the Faculty of Dentistry. Exclusion criteria were records of patients aged $<19$ years with any pathological dentoalveolar condition, any craniofacial anomaly or syndrome such as Down syndrome, cleidocranial dysostosis or the presence of incomplete records or poor-quality orthopantomograms, incomplete root formation of third molars or absence of adjacent second molars, a history of any dental extraction or orthodontic treatment. When reviewing panoramic radiographs, clinical records of patients were also examined, and related symptoms including pain, pericoronitis, lymphadenopathy (LAP) and trismus were noted for every patient. All impacted third molar teeth on panoramic radiographs were reviewed by a single examiner (S.Y.) using a Cliniview 10.0.2 (Instrumentarium, Tuusula, Finland) X-ray viewer to determine the levels of eruption and angulations. In order to minimize the risk of false assessments caused by fatigue, no more than 50 radiographs were evaluated at a time. The depth of impacted lower third molars in relation to the occlusal plane was recorded according to the classification of Pell and Gregory (fig. 1). The angulation of an impacted third molar was documented based on Winter's classification with reference to the angle formed between the intersected longitudinal axes of the second and third molars (fig. 2). The distance from the ramus to the distal surface of the second molar (retromolar space) was also measured (fig. 3).

Distributions of obtained values were compared using a Pearson $\chi^{2}$ test, using the Statistical Package for the Social Sciences 22 software. Distribution of retromolar space was tested for normality using Kolmogorov-Smirnov and Shapiro-Wilk tests. When the retromolar space was not found to be normally distributed ( $\mathrm{p}<$ 0.05 ), the Mann-Whitney $U$ test was used to compare 2-group variables. The Kruskal-Wallis test and pairwise comparisons were used to compare 3-group variables. One hundred panoramic radiographs were re-evaluated after an interval of 1 week to measure intraexaminer error. The Cohen kappa coefficient was found to be $91 \%$.

\section{Results}

Of the 705 patients (mean age: $30.58 \pm 11.98$ years, range: 19-73) with at least 1 impacted third molar tooth, $335(47.5 \%)$ were males and 370 (52.5\%) were females; the difference was not statistically significant $(\mathrm{p}=0.187)$. From the 705 patients, a total of 2,133 impacted third molar teeth was examined - maxilla: 1,037 (49\%) and mandible: 1,096 (51\%) -, and the difference was not statistically significant either $(\mathrm{p}=0.201)$. The distribution of third molars by level of impaction and angulation is shown in table 1 . The most common angulation of impaction in both maxillae and mandibulae was vertical. Level B impaction was the most common in the maxilla $(425 ; 39 \%)$, while level C impaction was the most common in the mandible $(635 ; 61 \%)$. The distribution of symptoms by gender and area of jaw is shown in table 2 . Pain $(272 ; 39 \%)$ and pericoronitis $(188 ; 27 \%)$ were the 
Table 1. Distribution (numbers, percentages in parentheses) of third molar impaction by level of impaction and angulation

\begin{tabular}{|c|c|c|c|c|c|c|c|c|c|c|}
\hline & \multicolumn{4}{|c|}{ Level of impaction } & \multicolumn{6}{|c|}{ Angulation } \\
\hline & $\mathrm{A}$ & B & $\mathrm{C}$ & $\mathrm{p}$ value & $\mathrm{M}$ & $\mathrm{D}$ & $\mathrm{V}$ & $\mathrm{H}$ & $\mathrm{O}$ & $\mathrm{p}$ value \\
\hline Maxillary impacts & $272(25)$ & $425(39)$ & $399(36)$ & $<0.01^{*}$ & $96(9)$ & $343(33)$ & $592(57)$ & $5(0.5)$ & $1(0.1)$ & $<0.01^{*}$ \\
\hline Mandibular impacts & $210(20)$ & $192(19)$ & $635(61)$ & & $313(29)$ & $144(13)$ & $585(53)$ & $53(5)$ & $1(0.1)$ & \\
\hline Total & $482(23)$ & $617(29)$ & $1,034(48)$ & & 409 (19) & $487(23)$ & $1,177(55)$ & $58(3)$ & $2(0.1)$ & \\
\hline
\end{tabular}

* $\mathrm{p}<$ 0.05: statistically significantly different. $\mathrm{M}=$ Mesioangular; $\mathrm{D}=$ distoangular; $\mathrm{V}=$ vertical; $\mathrm{H}=$ horizontal; $\mathrm{O}=$ other.

Table 2. Distribution (numbers, percentages in parentheses) of symptoms by gender and area of jaw

\begin{tabular}{|c|c|c|c|c|c|c|c|c|}
\hline & \multicolumn{4}{|l|}{ Gender } & \multicolumn{4}{|c|}{ Area of jaw } \\
\hline & $\begin{array}{l}\text { male } \\
(\mathrm{n}=335)\end{array}$ & $\begin{array}{l}\text { female } \\
(\mathrm{n}=370)\end{array}$ & $\begin{array}{l}\text { total } \\
(\mathrm{n}=705)\end{array}$ & $\mathrm{p}$ value & $\begin{array}{l}\text { maxillary } \\
\text { impacts } \\
(\mathrm{n}=1,037)\end{array}$ & $\begin{array}{l}\text { mandibular } \\
\text { impacts } \\
(\mathrm{n}=1,096)\end{array}$ & $\begin{array}{l}\text { total } \\
(\mathrm{n}=2,133)\end{array}$ & $\mathrm{p}$ value \\
\hline Pain & $131(39)$ & $141(38)$ & $272(39)$ & 0.786 & 404 (39) & $447(41)$ & $851(40)$ & 0.389 \\
\hline Pericoronitis & $101(30)$ & $87(24)$ & $188(27)$ & $0.027^{*}$ & $16(2)$ & $236(22)$ & $252(12)$ & $<0.001^{*}$ \\
\hline LAP & $47(14)$ & $41(11)$ & $88(12)$ & 0.237 & $132(13)$ & $159(15)$ & $291(14)$ & 0.232 \\
\hline Trismus & $36(11)$ & $35(9)$ & $71(10)$ & 0.571 & $103(10)$ & $125(11)$ & $228(11)$ & 0.271 \\
\hline
\end{tabular}

$* \mathrm{p}<0.05$ : statistically significantly different.

Table 3. Distribution (numbers, percentages in parentheses) of symptoms by level of impaction and angulation

\begin{tabular}{|c|c|c|c|c|c|c|c|c|c|}
\hline & \multicolumn{4}{|c|}{ Level of impaction } & \multicolumn{5}{|c|}{ Angulation } \\
\hline Pericoronitis & $112(44)$ & $107(42)$ & $33(14)$ & $<0.01^{*}$ & $75(30)$ & $64(25)$ & $101(40)$ & $12(5)$ & $<0.01^{*}$ \\
\hline LAP & $112(38)$ & $88(30)$ & $91(32)$ & $<0.01^{*}$ & $61(21)$ & $75(26)$ & $148(51)$ & $7(2)$ & $<0.01^{*}$ \\
\hline Trismus & $87(38)$ & $84(37)$ & $57(25)$ & $<0.01^{*}$ & $42(18)$ & $71(31)$ & $107(47)$ & $8(4)$ & $<0.01^{*}$ \\
\hline
\end{tabular}

${ }^{*} \mathrm{p}<0.05$ : statistically significantly different. $\mathrm{M}=$ Mesioangular; $\mathrm{D}=$ distoangular; $\mathrm{V}=$ vertical; $\mathrm{H}=$ horizontal.

most common complications of impaction, followed by LAP $(88 ; 12 \%)$ and trismus $(70 ; 10 \%)$. There was no significant difference in frequency of pain, LAP and trismus between genders and areas of jaw. Pericoronitis was more prevalent in males $(101 ; 30 \%)$ than females and was usually related to lower third molars $(236 ; 22 \%)$. The distribution of symptoms showed significant differences by level of impaction and angulation $(\mathrm{p}<0.01)$, as presented in table 3 . The occurrence rate of symptoms showed higher percentages for pain $(318 ; 37 \%)$, pericoronitis $(112 ; 44 \%)$, LAP $(112 ; 38 \%)$ and trismus $(87 ; 38 \%)$ at level A impaction than other impaction levels. Also it was noted that most of the symptoms of pain $(408 ; 48 \%)$, pericoronitis $(101 ; 40 \%)$, LAP $(148 ; 51 \%)$ and trismus (107; 47\%) were associated with vertically angulated third molars. The retromolar space was significantly smaller in females $(13.8 \mathrm{~mm})$ than males $(11.9 \mathrm{~mm}$; $\mathrm{p}<$ $0.05)$. Moreover there was a significant difference in retromolar space for the area of jaw (maxillary: $11.3 \mathrm{~mm}$; mandibular: $14.2 \mathrm{~mm}$ ) and impaction level (A: $14.7 \mathrm{~mm}$; B: $11.1 \mathrm{~mm}$; C: $10.3 \mathrm{~mm}$; $<0.01$; table 4). Pairwise comparisons indicated that the retromolar space showed different results for impaction levels (table 5). 
Table 4. Means and SD of retromolar space $(\mathrm{mm})$ by gender, area of jaw and level of impaction

\begin{tabular}{lccc}
\hline & Mean & SD & p value \\
\hline Gender & & & $<0.01^{*}$ \\
$\quad$ Male & 13.8 & 5.63 & \\
$\quad$ Female & 11.9 & 2.85 & \\
Area of jaw & & & $<0.01^{*}$ \\
$\quad$ Maxillary & 11.3 & 4.41 & \\
$\quad$ Mandibular & 14.2 & 2.65 & $<0.01^{*}$ \\
Level of impaction & & & \\
$\quad$ A & 14.7 & 2.12 & \\
B & 11.1 & 3.14 & \\
C & 10.3 & 1.86 & \\
\hline
\end{tabular}

Gender and area of jaw assessed by the Mann-Whitney U test, level of impaction by the Kruskal-Wallis test. ${ }^{*} \mathrm{p}<0.05$ : statistically significantly different.

Table 5. Pairwise comparisons of impaction levels for the retromolar space

\begin{tabular}{llllll}
\hline $\begin{array}{l}\text { Comparison } \\
\text { groups }\end{array}$ & $\begin{array}{l}\text { Test } \\
\text { statistics }\end{array}$ & $\begin{array}{l}\text { Standard } \\
\text { error }\end{array}$ & $\begin{array}{l}\text { Standard } \\
\text { test } \\
\text { statistics }\end{array}$ & p value & $\begin{array}{l}\text { Adjusted } \\
\text { p value }\end{array}$ \\
\hline C-B & 564.601 & 31.245 & 18.070 & $<0.001^{*}$ & $<0.001^{*}$ \\
C-A & $1,021.125$ & 34.374 & 29.706 & $<0.001^{*}$ & $<0.001^{*}$ \\
B-A & 456.524 & 38.165 & 11.962 & $<0.001^{*}$ & $<0.001^{*}$ \\
\hline
\end{tabular}

${ }^{*} \mathrm{p}<0.05$ : statistically significantly different.

\section{Discussion}

This study showed a high prevalence rate of third molar impaction in the vertical position. This finding confirmed the previous studies of Almendros-Marqués et al. [4], Bataineh et al. [9] and Hugoson and Kugelberg [10], who had reported that the most common angulation was vertical. However, other studies had shown that the most common type was mesioangular impaction $[11,12]$. The level of impaction assessed based on the Pell and Gregory classification showed that level B impaction was the most common in the maxilla, similar to the study of Hassan [1], while that of level $\mathrm{C}$ was the most common in the mandible. These findings conflict with most of the previous studies that identified the most common position as level A $[7,13,14]$. Further results also conflict with Blondeau and Nach [15] from Canada, and Almendros-Marqués et al. [4] from Spain reported level B as the most common position of mandibular third molars. These differences in angulation and level of impaction could be due to the difference in race, patient selection criteria and study population. Hereof Richardson [16] and Ventä et al. [17] suggested that it would be inaccurate to predict the eruption or impaction of third molars before the age of 20 years because of continuous positional changes during further development.

Pericoronitis is a soft tissue infection located around the crown of a partially impacted tooth, whose appearance implies the accumulation of microorganisms and food remains [4]. The impact of gender on the development and frequency of pericoronitis has been reported in the literature. In the present study, we found a slight tendency in male patients for pericoronitis, but other symptoms showed no gender predominance. In contrast, Bataineh et al. [9] reported that pericoronitis cases were much more frequently seen in female patients than male patients. Likewise Yamalık and Bozkaya [18] found a predominance of females for pericoronitis. However, AlmendrosMarqués et al. [4] and Akarslan and Kocabay [2] found no gender predominance for all complaints and pathologies.

The finding of a higher prevalence rate of pericoronitis for impacted third molars in this study confirmed the previous studies of Jamileh and Pedlar [19] and Khawaja [20] that pericoronitis was the most common indication for removal of impacted mandibular third molars. A probable explanation could be that pericoronitis is a common pathological condition of the mandibular impacted teeth.

In the present study, the observation that angulation had a statistically significant impact on the development of pericoronitis and other clinical symptoms confirmed that vertical angulation was an important factor for the development of clinical symptoms. As previously suggested, Leone et al. [21] had reported that the third molars which were most likely to cause pericoronitis were vertical and slightly distoangular teeth. On the other hand, in the studies of Güngörmüs [22] and Kay [23] the majority of pericoronitis cases were reported to be involved with mesioangular impactions. Eventually, Polat et al. [3] suggested that most molars with pathoses were either in a vertical or in a mesioangular position, but this is because such positions have a higher frequency. In this regard, Murad et al. [24] suggested that these differences may be due to geographical variation related to diet.

The eruption level of third molars has also an impact on the development of clinical symptoms. In our study we observed that most of the impacted molars with pericoro- 
nitis had erupted to the same level as the adjacent second molar occlusal plane. Similar to our results, Halverson and Anderson [25] reported an association of pericoronitis with the third molar tooth at or below the height of the occlusal plane of the arch. Leone et al. [21] suggested a similar association with the third molar tooth at or above the occlusal plane. Ali et al. [26] suggested that these depths are generally associated more frequently with soft tissue impaction, forming a cuff over partially erupted teeth and starting pericoronitis.

Third molars are the teeth that most commonly follow an abortive eruption path and become impacted. Lack of space seems to be the major cause of abortive eruption. However, eruption cannot be guaranteed despite adequate space available in the jaw [27]. The development of space for the third molar is governed by many factors, including resorption of bone from the anterior border of the ramus, backward slope of the anterior border of the ramus in relation to the alveolar border, forward movement of the dentition, growth in length of the mandible and sagittal direction of mandibular growth [28]. In the present study, we found a significant difference in retromolar space for levels of impaction. Also the retromolar space seemed to decrease while the impaction level was increased. In accordance with our finding, Björk et al. [29] reported that the space behind the second molar was reduced in $90 \%$ of cases with mandibular third molar impaction. Ganss et al. [30] reported that when the retromolar space is $13.9 \mathrm{~mm}$ in women and $14.3 \mathrm{~mm}$ in men, the probability of eruption is 70\%. Later on, Ventä et al. [17] stated that if the retromolar space is at least $16.5 \mathrm{~mm}$, the probability of eruption is $100 \%$. With reference to these studies and our results, we can suggest that third molar teeth may be impacted if the retromolar space is lower than $13.8 \mathrm{~mm}$ for males and $11.9 \mathrm{~mm}$ for females in the Turkish population.

\section{Conclusion}

The pattern of third molar impaction in a Central Anatolian Turkish population was characterized by a high prevalence rate of level $\mathrm{C}$ impaction with vertical position. Pain and pericoronitis were the most common symptoms usually associated with level A impaction and vertical position. Male patients with an impacted lower third molar had a tendency to develop pericoronitis. The retromolar space influenced the impaction level.

\section{References}

1 Hassan AH: Pattern of third molar impaction in a Saudi population. Clin Cosmet Investig Dent 2010;2:109-113.

2 Akarslan ZZ, Kocabay C: Assessment of the associated symptoms, pathologies, positions and angulations of bilateral occurring mandibular third molars: is there any similarity? Oral Surg Oral Med Oral Pathol Oral Radiol 2009;108:e26-e32.

-3 Polat HB, Özan F, Kara I, et al: Prevalence of commonly found pathoses associated with mandibular impacted third molars based on panoramic radiographs in a Turkish population. Oral Surg Oral Med Oral Pathol Oral Radiol 2008; 105:e41-e47.

-4 Almendros-Marqués N, Berini-Aytés L, GayEscoda C: Influence of lower third molar position on the incidence of preoperative complications. Oral Surg Oral Med Oral Pathol Oral Radiol 2006;102:725-732.

5 Tuzuner Oncul AM, Yazicioglu D, Alanoglu $Z$, et al: Postoperative analgesia in impacted third molar surgery: the role of preoperative diclofenac sodium, paracetamol and lornoxicam. Med Princ Pract 2011;20:470-476.
-6 Malkawi Z, Al-Omiri MK, Khraisat A: Risk indicators of postoperative complications following surgical extraction of lower third molars. Med Princ Pract 2011;20:321-325.

7 Hashemipour MA, Tahmasbi-Arashlow M, Fahimi-Hanzaei F: Incidence of impacted mandibular and maxillary third molars: a radiographic study in a Southeast Iran population. Med Oral Patol Oral Cir Bucal 2013; 18:e140-e145.

8 Doğan N, Orhan K, Günaydin Y, et al: Unerupted mandibular third molars: symptoms, associated pathologies, and indications for removal in a Turkish population. Quintessence Int 2007;38:e497-e505.

-9 Bataineh AB, Albashaireh ZS, Hazza'a AM: The surgical removal of mandibular third molars: a study in decision making. Quintessence Int 2002;33:613-617.

10 Hugoson A, Kugelberg CF: The prevalence of third molars in a Swedish population. An epidemiological study. Community Dent Health 1988;5:121-138.

11 Meisami T, Sojat A, Sàndor GK, et al: Impacted third molars and risk of angle fracture. Int J Oral Maxillofac Surg 2002;31:140-144.
12 Chaparro-Avendaño AV, Pérez-García $S$ Valmaseda-Castellón E, et al: Morbidity of third molar extraction in patients between 12 and 18 years of age. Med Oral Patol Oral Cir Bucal 2005;10:422-431.

13 Obiechina AE, Arotiba JT, Fasola AO: Third molar impaction: evaluation of the symptoms and pattern of impaction of mandibular third molar teeth in Nigerians. Odontostomatol Trop 2001;24:22-25.

14 Monaco G, Montevecchi M, Bonetti GA, et al Reliability of panoramic radiography in evaluating the topographic relationship between the mandibular canal and impacted third molars. J Am Dent Assoc 2004; 135:312-318.

15 Blondeau F, Nach GD: Extraction of impacted mandibular third molars: postoperative complications and their risk factors. J Can Dent Assoc 2007;73:325.

16 Richardson M: Changes in lower third molar position in the young adult. Am J Orthod Dentofacial Orthop 1992;102:320-327.

17 Ventä I, Murtomaa H, Turtola L, et al: Assessing the eruption of lower third molars on the basis of radiographic features. Br J Oral Maxillofac Surg 1991;29:259-262. 
18 Yamalık K, Bozkaya S: The predictivity of mandibular third molar position as a risk indicator for pericoronitis. Clin Oral Investig 2008;12:9-14.

19 Jamileh Y, Pedlar J: Effect of clinical guidelines on practice for extraction of lower third molars: study of referrals in 1997 and 2000. Br J Oral Maxillofac Surg 2003;41:371-375.

20 Khawaja AN: Third molar impaction. A review. Pak Oral Dent J 2006;15:97-101.

21 Leone SA, Edenfield MJ, Cohen ME: Correlation of acute pericoronitis and the position of the mandibular third molar. Oral Surg Oral Med Oral Pathol Oral Radiol 1986;62:245250.
22 Güngörmüs M: Pathologic status and changes in mandibular third molar position during orthodontic treatment. J Contemp Dent Pract 2002;15:11-22.

23 Kay LW: Investigations into the nature of pericoronitis. Br J Oral Surg 1966;3:188-205.

24 Murad N, Khan MY, Abdulqaiyum F: Predisposing factors for the infection of mandibular third molar. Pak Oral Dent J 2013;33:253256.

25 Halverson BA, Anderson WH: The mandibular third molar position as a predictive criterion for risk for pericoronitis: a retrospective study. Mil Med 1992;157:142-145.

26 Ali S, Nazır A, Ali-Shah SA, Akhtar MU: Dental caries and pericoronitis associated with impacted mandibular third molars - a clinical and radiographic study. Pak Oral Dent J 2014; 34:268-273.
27 Sandhu S, Kaur T: Radiographic evaluation of the status of third molars in the Asian-Indian students. J Oral Maxillofac Surg 2005;63:640645.

28 Richardson ME: Lower third molar space. Angle Orthod 1987;57:155-161.

29 Björk A, Jensen E, Palling M: Mandibular growth and third molar impaction. Acta Odontol Scand 1956;14:231-272.

30 Ganss C, Hochban W, Kielbassa AM, et al: Prognosis of third molar eruption. Oral Surg Oral Med Oral Pathol Oral Radiol 1993;76: 688-693. 